\title{
A participação oral em uma sala de aula de Escola Pública: modelos interacionais na construção conjunta (ou não) do

\author{
conhecimento
}

\begin{abstract}
Resumo: O objetivo deste artigo é discutir como é organizada a participação oral nas aulas de uma 3. ${ }^{a}$ série do Ensino Médio de uma Escola Pública no sudeste do Paraná e apontar como os modos de participação podem contribuir para a construção conjunta do conhecimento. Para isso, foram utilizados os procedimentos teórico-metodológicos da Análise da Conversação Etnometodológica para a análise microetnográfica de 18 horas de dados audiovisuais de aulas. Os resultados mostram que a participação oral dessa turma nas aulas se dá tipicamente pelo modelo interacional Iniciação, Resposta e Avaliação (IRA), o qual consiste em fazer testagens do que os alunos já sabem, o que não oportuniza muito espaço para construção conjunta de conhecimento. No entanto, embora que com menor frequência, o modelo IRA também é utilizado de uma maneira não tradicional (GARCEZ, 2006) para levar os alunos a participarem oralmente na produção das atividades. Desse modo, a partir dos dados de fala-em-interação das aulas analisadas, evidencia-se a importância do modo de organização da interação nas aulas para a construção conjunta e participativa do conhecimento em sala de aula.
\end{abstract}

Palavras-chave: participação oral; construção conjunta do conhecimento; sala de aula.

\begin{abstract}
The aim of this paper is to discuss how the oral participation on 3th level of Secondary Education Class in a public school in southeast Paraná is organized and to show how the modes of participation in this class may contribute to the joint construction of knowledge. We used the theoretical and methodological procedures of Ethnomethodological Conversation Analysis for a microethnographic analysis of 18 hours of audiovisual data. The results show that in this class the oral participation is given by the typically interactional model, Initiation, Response and Assessment (IRA), which consists in testing what students already know. However, although with less frequency, the IRA model is also used in a non-traditional model (GARCEZ, 2006) to lead students to participate orally in activities production. Thus, from the talk-in-interaction data, the interaction analysis point out the importance of the organizational interaction in the classroom for the joint construction of knowledge and participation in the classroom.
\end{abstract}

Key-words: oral participation, joint construction of knowledge; classroom.

\footnotetext{
* Doutoranda em Letras na Universidade Estadual de Maringá (UEM), professora e coordenadora do curso de Letras da Faculdade Alvorada de Tecnologia e Educação de Maringá.
} 


\section{Introdução}

No contexto escolar, seja nas aulas de línguas ou não, a participação tem sido discutida por educadores e problematizada em pesquisas. Estudos têm apontado que participar em uma aula não requer necessariamente que essa participação seja oral, pois um aluno pode sinalizar a participação por pistas não-vocais.

No entanto, trabalhos têm problematizado e mostrado a importância de se dar a palavra e de se ter a palavra em sala de aula (SCHULZ, 2007), principalmente, para o desenvolvimento crítico e de cidadania. Ainda em articulação com outros estudos, espaços de participação oral em sala de aula podem significar oportunidades para a ampliação do espaço para a construção conjunta do conhecimento. ${ }^{1}$

Assim, a organização da interação, da fala-em-interação em sala de aula, dos momentos de quem fala, quando fala e com quem fala, algo natural e cotidiano, pode contribuir para uma efetiva construção conjunta do conhecimento.

Alguns modelos interacionais foram descritos para o estudo da interação e participação em sala de aula: estruturas de participação (PHILIPS, 2001); o sistema de McHoul (1978); o padrão interacional Iniciação-Resposta-Avaliação (IRA) proposto por Sinclair e Coulthard (1975); e o revozeamento de O'Connor e Michaels (1996) e a participação exuberante (RAMPTON, 2006).

Nesse sentido, pesquisas têm sido desenvolvidas, buscando a compreender e interpretar a participação em sala de aula, enfatizando quais modelos interacionais contribuem para uma participação mais igualitária, efetiva e conjunta em sala de aula. Esses estudos são relevantes, pois podem auxiliar não só para que sejam repensadas e reorganizadas as práticas de participação nesses contextos pesquisados, mas em outros contextos.

Nessa perspectiva, o presente artigo apresenta o resultado de uma análise microetnográfica ${ }^{2}$ dos modos de participação nas aulas de uma 3. ${ }^{a}$ série de do Ensino Médio de uma escola pública no sudeste do Paraná, apontando como a participação

\footnotetext{
${ }^{1}$ Como as pessoas por uma série de práticas operacionalizam ações e atitudes orientadas para a confirmação, modificação ou ampliação do conhecimento (ABELEDO, 2008).

2 Os dados e a análise apresentada fazem parte da dissertação de mestrado em Letras, intitulada "Letramento e identidades sociais em um município multilíngue no Paraná", a qual foi orientada pela

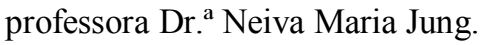


nessa sala de aula pode ou não contribuir para a construção conjunta do conhecimento. Assim, primeiramente, no artigo são enfocados os modelos interacionais descritos para sala de aula, na sequência é apresentado o pressuposto teórico-metodológico que norteia a análise dos dados, a Análise da Conversa Etnometodológica, na sequência são apresentados os procedimentos metodológicos e, posteriormente, a análise de dados de sala de aula, por fim, são tecidas considerações finais.

\section{Modelos interacionais em sala de aula}

Nesta seção serão apresentados alguns modelos interacionais descritos para o estudo da interação e participação em sala de aula, a saber: estruturas de participação (PHILIPS, 2001), o sistema de McHoul (1978), o padrão interacional IniciaçãoResposta-Avaliação (IRA) (Sinclair; Coulthard, 1975) e o revozeamento (O’Connor; Michaels, 1996).

Na sala de aula, Philips (2001) descreve a estrutura de participação através de quatro modos: no primeiro, o professor interage com toda a turma, selecionando a turma inteira como interlocutor; no segundo, o professor interage com alguns alunos ou somente com grupos específicos de alunos; no terceiro e no quarto modo, os alunos interagem sozinhos.

O modelo de McHoul (1978) contempla o caráter institucional da fala-eminteração para sala de aula tradicional. Dentre as regras de participação descritas nesse modelo, na regra I(A), é dado ao professor a alocação do turno inicial e a seleção do próximo falante, nenhum outro falante tem o direito de tomar o turno. Na regra II(A), o turno do aluno selecionado pelo professor deve ser substituído pelo professor e não por outro falante, no caso, o aluno. Por fim, de acordo com a regra III(C), o turno do aluno selecionado não envolve o uso da técnica o falante atual seleciona o próximo, então o aluno pode continuar falando a menos que o professor se auto selecione.

Nas regras do sistema de tomada de turno de McHoul (1978), o direito à alocação de turnos nos lugares relevantes para a transição é dado ao professor. Jung e Gonzalez (2009) enfatizaram que a própria composição das regras de McHoul já define que a alocação dos turnos deve ser feita pelo professor e não por um falante em geral. 
Sendo assim, a regra descreve aprioristicamente uma assimetria existente na fala-eminteração na sala de aula tradicional.

Outro modelo de sequência interacional foi descrito por Sinclair e Coulthard (1975) como Iniciação-Resposta-Avaliação (IRA). A organização do IRA consiste de uma estrutura tripartite, pergunta, resposta e avaliação, sendo que sempre a iniciação é feita pelo professor, característica que também é identificada no modelo de McHoul (1978).

Essa sequência interacional descreve uma das ações mais empreendidas em sala de aula, pois o professor pergunta, o aluno responde e o professor avalia ratificando positiva ou negativamente a resposta do aluno. É importante ressaltar ainda que no IRA, segundo Garcez (2006), o professor faz uma pergunta para a qual já tem uma resposta, ou seja, testa o aluno simulando o desconhecimento de uma resposta por ele já conhecida.

Entretanto, a estrutura tripartite do IRA pode ser usada na sala de aula, não somente testagem do que o aluno sabe, seguida da avaliação positiva ou negativa da resposta desse aluno, o que, de certo modo, limita a participação dele, mas também para um percurso para a co-construção da participação em aula, caracterizando o que Garcez (2006) destaca como IRA no discurso de sala de aula convencional não transgressivo, o qual tem o objetivo por meio das perguntas não somente de testar o que o aluno sabe, mas de fazer com que ele participe, desse modo o professor faz várias iniciações para que o aluno tome o turno.

Diferente do modelo IRA, há um modelo interacional identificado e descrito por O’Connor e Michaels (1996), o Revoicing ou revozeamento. Nessa prática o professor, no lugar de utilizar a sequência IRA, faz uso do revozeamento, ou seja, rediz do turno anterior para reexame pelo seu produtor (GARCEZ, 2006). No lugar de avaliar o que o aluno diz, a professora repete o turno do aluno, para que ele, além de ser ratificado, possa ter seu trabalho desenvolvido, uma vez que seu turno torna-se relevante para a interação.

Dessa maneira, o revozeamento possibilita um melhor desenvolvimento da falaem-interação em sala de aula na perspectiva da construção conjunta de conhecimento. Contudo, como destaca Garcez (2006), o trabalho com o revozeamento exige estudo e 
trabalho, precisa ser fundamentado e co-construído gradativamente, sempre considerando as condições e possibilidades do contexto interacional.

Entretanto, na sala de aula contemporânea, Rampton (2006) ressalta que, a participação nem sempre acontece seguindo uma organização canônica. A sala de aula moderna apresenta muitas vezes uma organização diferenciada, na qual o aluno pode fazer a iniciação ou avaliar o professor.

Enfim, esses são alguns modelos interacionais apresentados para o estudo da interação e participação na sala de aula. Na próxima seção serão abordados pressupostos teóricos e metodológicos que subsidiarão a análise de dados de interação em sala de aula deste estudo.

\section{Pressupostos teóricos e metodológicos para o estudo da participação e interação: A Análise da Conversa Etnometodológica}

Para estudar a participação é mister considerar também a sequencialidade da tomada de turnos (GOODWIN; GOODWIN; 2004); turno a turno se co-sustenta o contexto institucional e a participação (SCHULZ, 2007).

Nessa perspectiva, é preciso analisar o uso da linguagem como ação social e conjunta (CLARK, 2000). Pelo uso da linguagem, as pessoas praticam ações sociais, fazem coisas, como por exemplo, participar em uma aula. Para isso, a perspectiva teórico-metodológica da Análise da Conversa Etnometodológica (ACE) é fundamental, por tratar a linguagem como ação social que pode ser evidenciada na sequencialidade ${ }^{3}$ da fala-em-interação, a qual, de acordo com Garcez (2006), "inclui as atividades vocais e não-vocais constituintes da interação social humana e que engloba todas as formas faladas de uso da linguagem em interação social, institucionais ou não, em co-presença ou não" (p. 66).

A ACE foi fundada por sociólogos norte-americanos, no final da década de 1960, preocupados em entender a natureza da ação social (GARCEZ, 2008) e busca interpretar a fala-em-interação a partir das ações que são co-construídas pelos participantes engajados na conversa.

\footnotetext{
${ }^{3}$ Sequencialidade "refere-se ao fato de que as ações constituídas pelo uso da linguagem são organizadas em sequências de elocuções produzidas por diferentes participantes" (LODER, 2008, p. 40).
} 
De acordo com a ACE há duas organizações fundamentais que regulam o uso da linguagem: a organização de tomada de turnos (SACKS; SCHEGLOFF; JEFFERSON, 1974) e a organização do reparo (SCHEGLOFF; JEFFERSON; SACKS, 1977).

Fortes (2009) salienta que a sistemática da organização da tomada de turno na conversa cotidiana e a organização do reparo, como práticas interacionais dos participantes, são recursos analíticos para o alcance do entendimento comum na falaem-interação como uma realização intersubjetiva. Desse modo, precisamos analisar a organização da tomada de turnos para evidenciar as ações que são realizadas e como os participantes mantêm o entendimento do que fazem em comum, por exemplo, participar de um evento aula.

Quanto a organização de tomada de turnos, de acordo com Schegloff (1992b apud FREITAS; MACHADO, 2008), os turnos são sequências de fala de um participante da conversa, são segmentos construídos a partir de Unidades de Construção de Turno (UCTs) e podem corresponder a unidades, como sentenças, orações, palavras isoladas, locuções frasais e recursos prosódicos. Deste modo, um turno não precisa necessariamente ser uma frase completa, mas uma palavra, uma exclamação etc.

Na sequencialidade dos turnos, um turno é seguido por outro, e o falante define o momento de troca de turno. Na perspectiva de Sacks, Schegloff, e Jefferson (1974/2005), os Locais Relevantes para Transição dos Turnos (LRT) são os lugares em que os falantes identificam uma possível completude de uma UCT e a possibilidade de fazer a troca de turno, o que pode ser sinalizado pela completude de um sintagma, pela entonação, pelo prolongamento de som, por um tempo de silêncio etc. (FREITAS; MACHADO, 2008).

Nesse sentido, definido que os turnos têm uma unidade de construção (UCT) que os compõem e também um lugar relevante de transição (LRT), é importante discorrer sobre a alocação dos turnos nos lugares relevantes (LRT). Apresentamos as práticas para alocação de turnos no quadro no quadro a seguir: 
[1] Para qualquer turno, no primeiro lugar relevante para a transição de uma primeira unidade de construção de turno:

[a] Se o turno até aqui está construído de modo a envolver o uso de uma técnica de 'falante corrente seleciona o próximo', então a parte assim selecionada tem o direito e é obrigada a tomar o turno seguinte para falar; nenhuma outra parte possui tais direitos ou obrigações, e a transferência ocorre naquele lugar.

b] Se o turno até aqui está construído de modo a não envolver o uso da técnica de 'falante corrente seleciona o próximo', então a auto-seleção para a próxima vez de falar pode ser instituída, mas não necessariamente; quem inicia primeiro adquire o direito ao turno, e a transferência ocorre naquele lugar.

[c] Se o turno até aqui está construído de forma a não envolver o uso da técnica de 'falante atual seleciona o próximo', então o falante corrente pode, mas não precisa continuar, a

\section{Quadro1. Prática de alocação de turnos.}

Desse modo, para a alocação dos turnos nos lugares relevantes para transição, há dois tipos de prática para a seleção dos próximos falantes: a seleção do próximo, quando o falante corrente seleciona o próximo falante; e a auto seleção, quando o próximo falante se autocandidata para tomar o turno (SACKS, SCHEGLOFF; JEFFERSON, 2005;FREITAS; MACHADO, 2008).

Assim como o sistema de tomada de turnos, o sistema de reparo também constitui a conversa. Schegloff, Jefferson e Sacks (1977) identificaram a recorrência sistemática de mecanismos para a resolução de problemas de escuta, produção e entendimento na fala-em-interação social que denominaram de sistema de reparo (LODER, 2008).

De acordo com Loder (2008), reparo caracteriza a identificação pelos interagentes de um problema na interação e, consequentemente, a tentativa de resolução do mesmo para fluência da interação. Schegloff, Jefferson e Sacks (1977) apresentam três trajetórias de reparo: 1) Reparo iniciado e levado a cabo pelo falante produtor da fonte de problema; 2) Reparo iniciado pelo falante da fonte de problema e levado a cabo pelo outro; 3) Reparo iniciado pelo outro e levado a cabo pelo falante produtor da fonte de problema (FORTES, 2009).

O sistema de reparo permite resolver problemas na interação e é fundamental para o sistema de tomada de turnos, para que a sequencialidade da interação não seja comprometida. Nesse sentido, o reparo está relacionado com a manutenção do 
entendimento comum, diferentemente da correção, restrita à substituição de um item considerado errado por outro correto (MACBETH, 2004).

O sistema de tomada de turno que foi descrito originalmente para a conversa cotidiana (SACKS; SCHEGLOFF; JEFFERSON, 1974) e depois adaptado para o estudo dos eventos de interação institucional (DREW; HERITAGE, 1992; CORONA, 2009; GONZALEZ; JUNG, 2009).

Corona (2009) afirma que o que caracteriza uma interação como institucional não é o ambiente físico em que essa se realiza, mas os objetivos a cumprir que fazem com que a interação seja institucional(DREW; HERITAGE, 1992). Sendo assim, as interações institucionais são pautadas pela necessidade de realização de uma tarefa institucional, por isso tendem a desenvolver formatos organizacionais para o cumprimento dessa tarefa.

No intuito de estudar a fala-em-interação em sala de aula, é preciso considerar que essa não é um processo que é determinado e instaurado por alguém a priori, isto é, não é o professor que individualmente constrói os modos de interação, da mesma forma que não são os alunos, mas, sim, ambos, professor e alunos co-constroem a interação por meio de ações que são guiadas por finalidades específicas, neste caso ensinar e aprender (DREW; HERITAGE, 1992 apud CORONA, 2009; JUNG; GONZALEZ, 2009).

$\mathrm{Na}$ próxima seção serão descritos, o contexto pesquisado, assim como os procedimentos analíticos que nortearam a análise de dados da interação na sala de aula.

\section{Procedimentos metodológicos}

Foram analisados $18 \mathrm{~h} 09 \mathrm{~m}$ e $37 \mathrm{~s}$ de dados audiovisuais da uma 3. ${ }^{\mathrm{a}}$ série do Ensino Médio de uma escola pública de um município localizado no sudeste do Paraná. Tais dados foram gerados por meio de uma abordagem qualitativo-interpretativa de cunho etnográfico (ERICKSON, 1989, 1992, 2001; DURANTI, 2000; MASON, 1996).

Para a análise desses dados registrados em áudio e vídeo, procuramos seguir dois aspectos cruciais às análises microetnográficas: identificar toda extensão da variação na interação no ambiente; estabelecer o que é típico e atípico, relativo à frequência de ocorrência (ERICKSON, 1992). 
Para isso, utilizamos procedimentos de análise de videoteipes adotados por Erickson e Shultz (2002). Neste estudo, os segmentos selecionados, foram transcritos com base nas convenções de transcrição da Análise da Conversa Etnometodológica, no Sistema Jefferson de transcrição adaptados de Loder (2008) e Bulla (2007). (As convenções de transcrição usadas neste estudo encontram-se em anexo). Seguindo os procedimentos de transcrição (LODER, 2008), os participantes são todos identificados por pseudônimos e as transcrições são realizadas de acordo com a variedade do português considerada culta, uma vez que o objetivo do estudo não consiste em apontar pontualmente as variações linguísticas usadas nas interações.

Na próxima seção, será apresentada como é construída a participação oral em sala de aula, enfocando quais são os modelos interacionais recorrentes e se tais modelos apontam para uma contribuição na construção conjunta de conhecimento.

\section{A participação típica e atípica em sala de aula de uma Escola Pública e os espaços para construção conjunta de conhecimento}

Para mostrar como acontece a participação nas aulas da 3. ${ }^{a}$ série do Ensino Médio, será apresentada a análise de dois segmentos interacionais, um evidenciado como típico nas aulas e outro como atípico. Esses segmentos são representativos no sentido de mostrar como acontece a participação nessa sala aula.

O primeiro segmento é de uma aula de Língua Portuguesa e mostra um tipo de interação e participação recorrente e típico nas aulas não só de Língua Portuguesa, mas de Língua Espanhola, Geografia e Sociologia, o modelo interacional tradicional de Iniciação, Resposta e Avaliação (IRA). Já o segundo segmento analisado representa um modelo interacional menos recorrente nas aulas, um uso do modelo IRA não tradicional (GARCEZ, 2006) para levar os alunos a participarem.

A sequência do primeiro evento acontece desse modo: um participante se autosseleciona e com a ratificação de Dalva faz a leitura, também durante essa leitura ela abre espaços para construção conjunta do sentido do texto. Conforme mostra o excerto a seguir: 
Excerto 1(Segmento 1 "Leitura e discussão do texto" - Aula de Português )

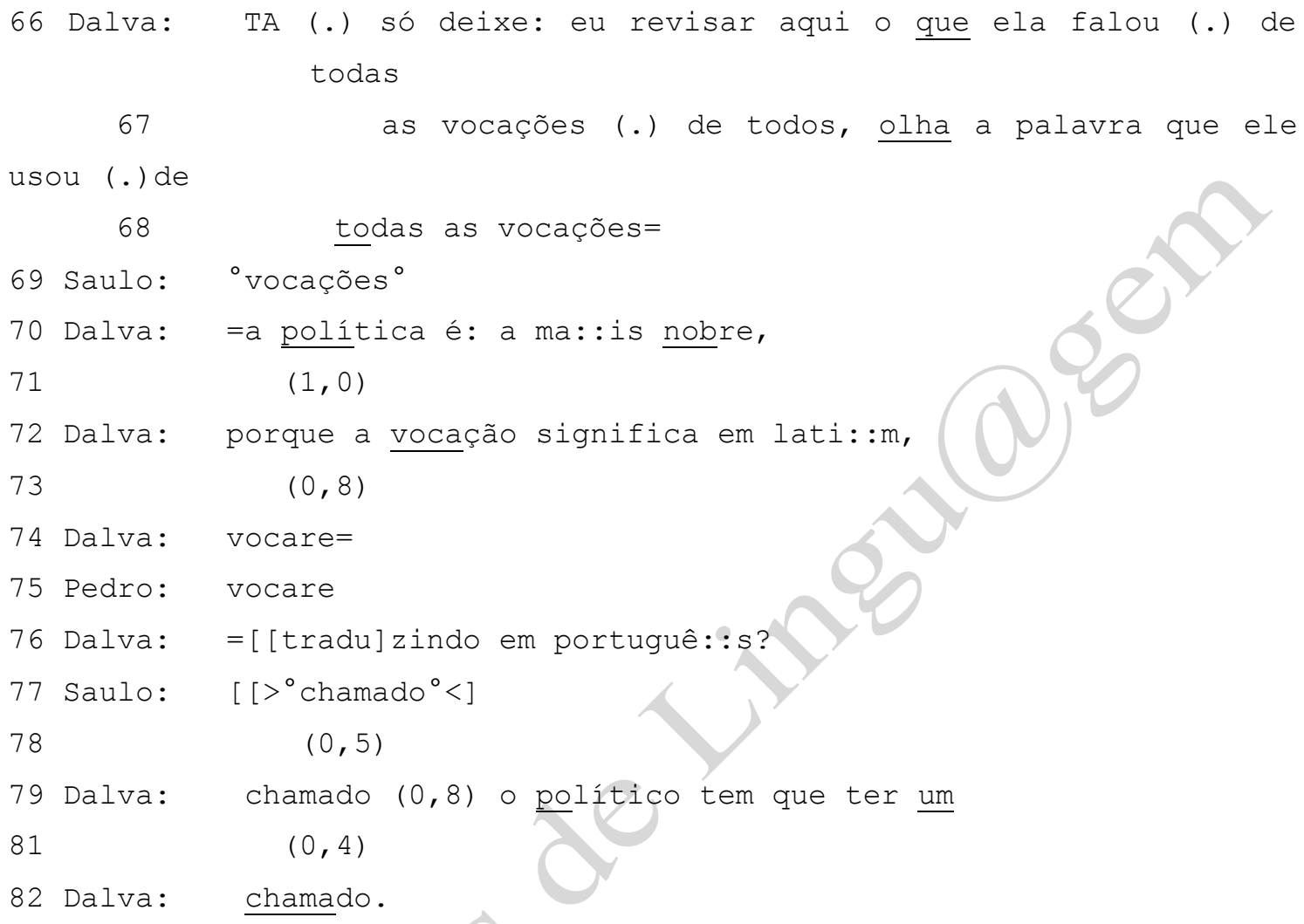

Dalva (linha 66),com alteração na intensidade de voz e ênfase em algumas palavras, procura alinhar os participantes no trabalho com o texto escrito $T A$ (.) só deixe: eu revisar aqui o que ela falou (.) de todas as vocações (.) de todos, olha a palavra que ele usou (.) de todas as vocações $=$,. Além disso, ela tenta direcionar a compreensão e interpretação do que foi lido, uma vez que nas linhas 67, 68 e 70 enfatiza de todas as vocações = a política é: a ma::is nobre, ou seja, a intensidade maior em determinadas sílabas e o prolongamento de som nas vogais das palavras afirmativas sugerem que a elocução é uma afirmação e não um questionamento. Embora na linha 71 tenha um silêncio de um segundo e este consista em um momento relevante para a transição de turno, os alunos não o fazem, o que pode ser justificado pelo fato de Dalva não fornecer pistas de estar usando a regra I(A) de McHoul (1978) ou a regra 1(a) (SACKS; SCHEGLOFF; JEFFERSON, 2005), na qual o falante atual seleciona o 
próximo falante para tomar o turno. Sendo assim, como nenhum próximo falante toma o turno, Dalva continua porque a vocação significa em lati::m,(linha 72). Nesse último turno, ela abre um espaço relevante para a transição de turno, sinalizado pelo prolongamento de som na última vogal e entonação de continuidade, o que é confirmado pela micropausa de oito décimos de segundo (linha 74). No entanto, ela novamente não obtém a resposta dos alunos e, em adjacência, toma o turno novamente fornecendo a resposta solicitada na iniciação vocare $=($ linha 74$)$.

$\mathrm{Na}$ linha 76, ela faz outra iniciação, marcada pelo prolongamento da vogal final e entonação ascendente $=[[$ tradu $]$ zindo em portuguê::s? . Concomitante e em sobreposição ao início do turno de Dalva, Saulo (linha 77) se autosseleciona com tom de voz baixo e fala acelerada, cita a tradução da palavra vocare para o português $\left[\left[>^{\circ}\right.\right.$ chamado $\left.^{\circ}<\right]$. No entanto, Saulo não é ratificado em adjacência por Dalva, o que se evidencia pelo espaço de tempo de cinco décimos de segundo (linha 78). E na sequência, ao invés de uma avaliação, Dalva, com ênfase em algumas sílabas e entonação descendente, apresenta a resposta correta para sua iniciação chamado(linha 82).

Na sequência, excerto 2, Dalva é quem continua organizando a participação no evento de letramento por meio da estrutura tripartite IRA.

Excerto 2(Segmento 1 "Leitura e discussão do texto" - Aula de Português)

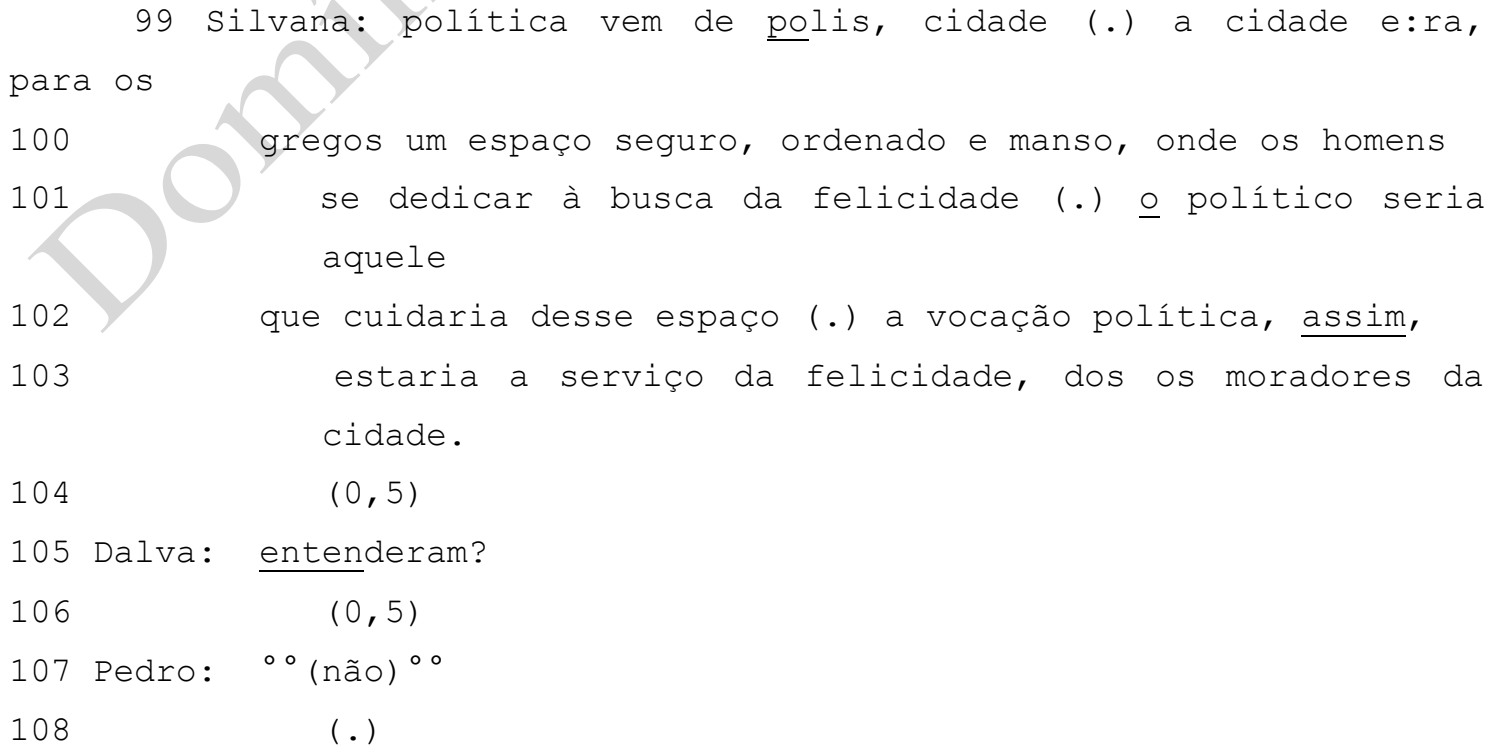




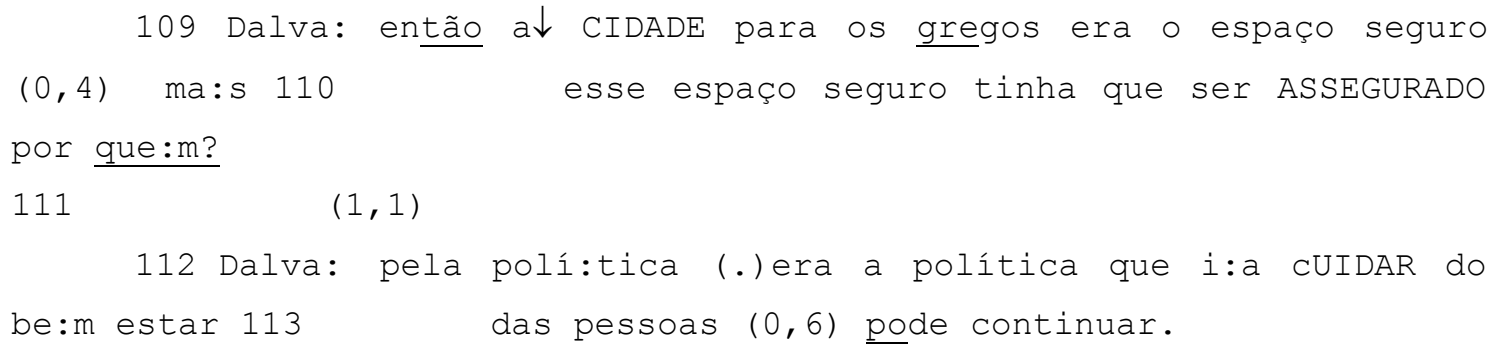

Após cinco décimos de segundos da realização da leitura em voz alta do texto por Silvana (linhas 99, 100, 101, 102 e 103), Dalva se autosseleciona com entonação ascendente, sinalizando tratar-se de uma pergunta entenderam? (linha 105), o que é confirmado pelo espaço relevante para transição de turno de cinco décimos de segundos (linha 106). Embora Dalva tenha endereçado todos alunos como interlocutores (PHILIPS, 2001), somente Pedro, depois de cinco décimos de segundo, se autosseleciona com intensidade de voz relativamente mais baixa e acusa o não entendimento ${ }^{\circ}(\text { não })^{\circ \circ}$ do conteúdo lido por Silvana. Dalva, após menos de três décimos de segundo (linha 108), toma o turno novamente e inicia a explicação do texto lido entãa a a CIDADE para os gregos era o espaço seguro $(0,4)$ (linha 109).

Nesse caso, não há construção conjunta do sentido do texto escrito, somente a apresentação de um sentido do que foi lido, fornecido por Dalva. Nas perguntas de iniciação (IRA) feitas por Dalva, por mais que os alunos estejam alinhados a sua fala, eles não tomam o turno e ela não busca engajá-los novamente, refazendo ou reformulando a pergunta. Ela fornece logo a resposta tida como correta e o sentido que quer conduzir. Pedro (linha 107) diz não saber a resposta, e inicia um reparo, mas Dalva não devolve a pergunta, ou não procura fazer com que Pedro tente apresentar o que tenha entendido. Ela, após uma pausa de três décimos de segundo apresenta, a interpretação do que foi lido então a CIDADE para os gregos era o espaço seguro $(0,4)$.

$\mathrm{Na}$ sequência o excerto analisado representa um uso do modelo IRA não tradicional, modo o qual foi menos recorrente nas aulas analisadas. $\mathrm{O}$ excerto 3 mostra que Helena procura engajar os alunos na produção escrita no quadro-negro. Esse engajamento dos alunos se dá basicamente também pela organização conversacional iniciação, resposta e avaliação (IRA) (SINCLAIR; COULTHARD, 1975). 
Excerto 3 (Segmento 2 "Construção conjunta de atividade no quadro" - Aula de História)

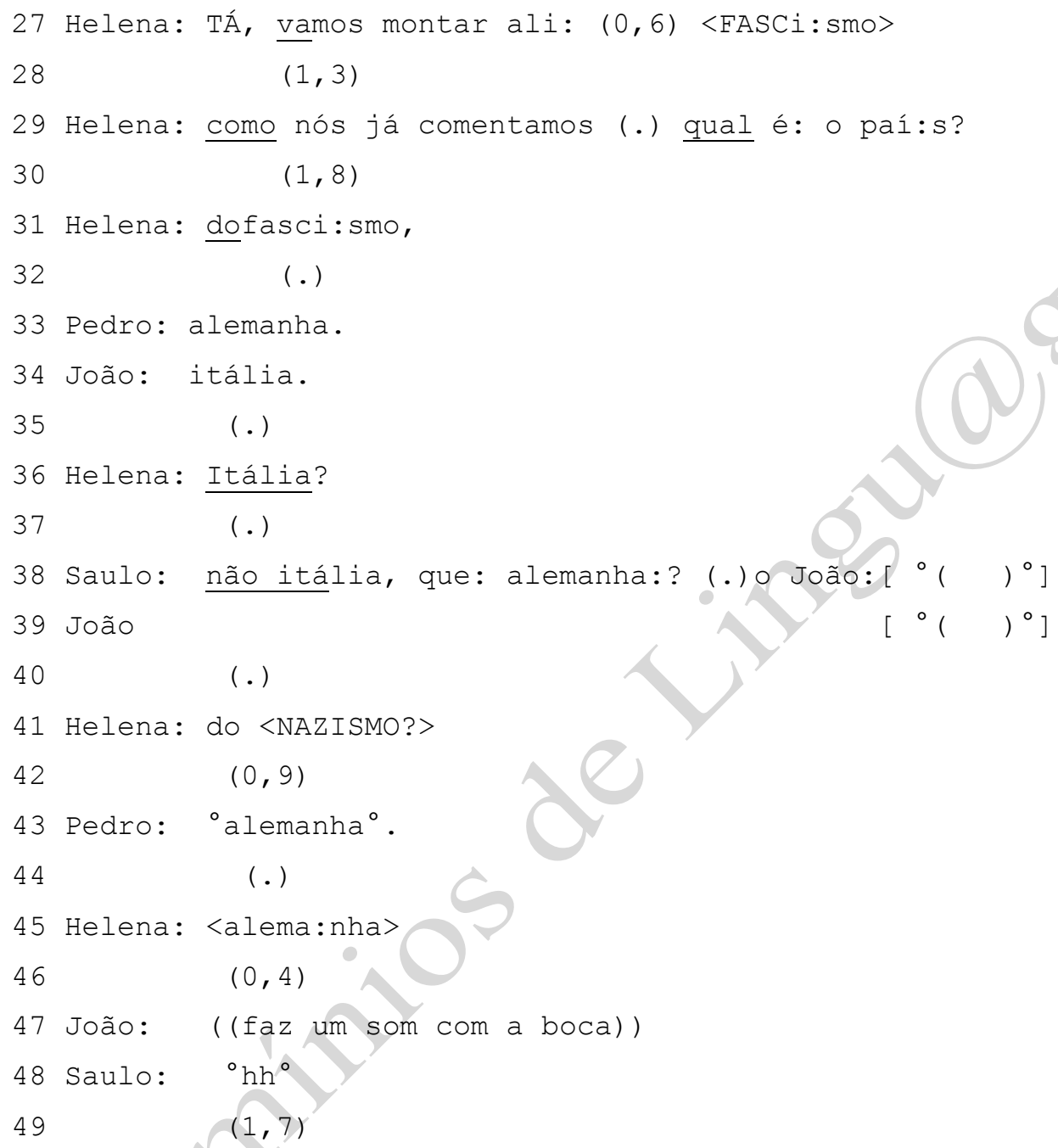

$\mathrm{Na}$ linha 27, primeiro, Helena orienta qual tópico será abordado e escrito no quadro síntese $\langle F A S C i: s m o>$. Na sequência, após escrever o tópico fascismo no quadro, ela faz uma iniciação endereçando sua fala a todos os alunos (PHILIPS, 2002) como nós já comentamos (.) qual é: o paí:s? (linha 29), com alterações na cadência rítmica, com intensidade maior e prolongamento de vogal nas palavras que denotam questionamento. Depois de um segundo e oito décimos de segundo (linha 30), como não obtém a resposta em adjacência, ela produz outra elocução também com prolongamento 
de vogal complementando sua iniciação dofasci:smo, (linha 31). Após uma pausa interturno de menos de três décimos de segundo, Pedro se autosseleciona e apresenta uma resposta alemanha. (linha 32). Na sequência, João também se autosseleciona e apresenta outra resposta itália. (linha 34). Depois de menos de três décimos de segundo (35), Helena toma o turno novamente e com intensidade maior e entonação ascendente Itália? (linha 36) repete a resposta de João (linha 34), avaliando-a como correta.

$\mathrm{Na}$ continuidade, Helena faz outra iniciação, marcada pelas alterações na cadência rítmica com fala desacelerada, intensidade de volume destacadamente maior e entonação ascendente do <NAZISMO?>(linha 41). Entretanto, a resposta para sua iniciação é dada após nove décimos de segundo por Pedro com entonação descendente e volume de voz baixo ${ }^{\circ}$ alemanha ${ }^{\circ}$. (linha 43). Após menos de três décimos de segundo, Helena, com cadência rítmica desacelerada e prolongamento de vogal, repete a resposta de Pedro <alema:nha> (linha 45) ratificando-a como correta e posteriormente a escreve no quadro.

Assim acontece a sequencialidade do evento: Helena faz a iniciação, os alunos dão a resposta, ela avalia e escreve a resposta no quadro síntese produzido no quadronegro. Entretanto, quando não obtém a resposta para a sua iniciação, Helena reformula a iniciação conforme apontado no excerto 4 , a seguir.

Excerto 4 (Segmento 2 "Construção conjunta de atividade no quadro" - Aula de História - 30/03/2009-00:22)

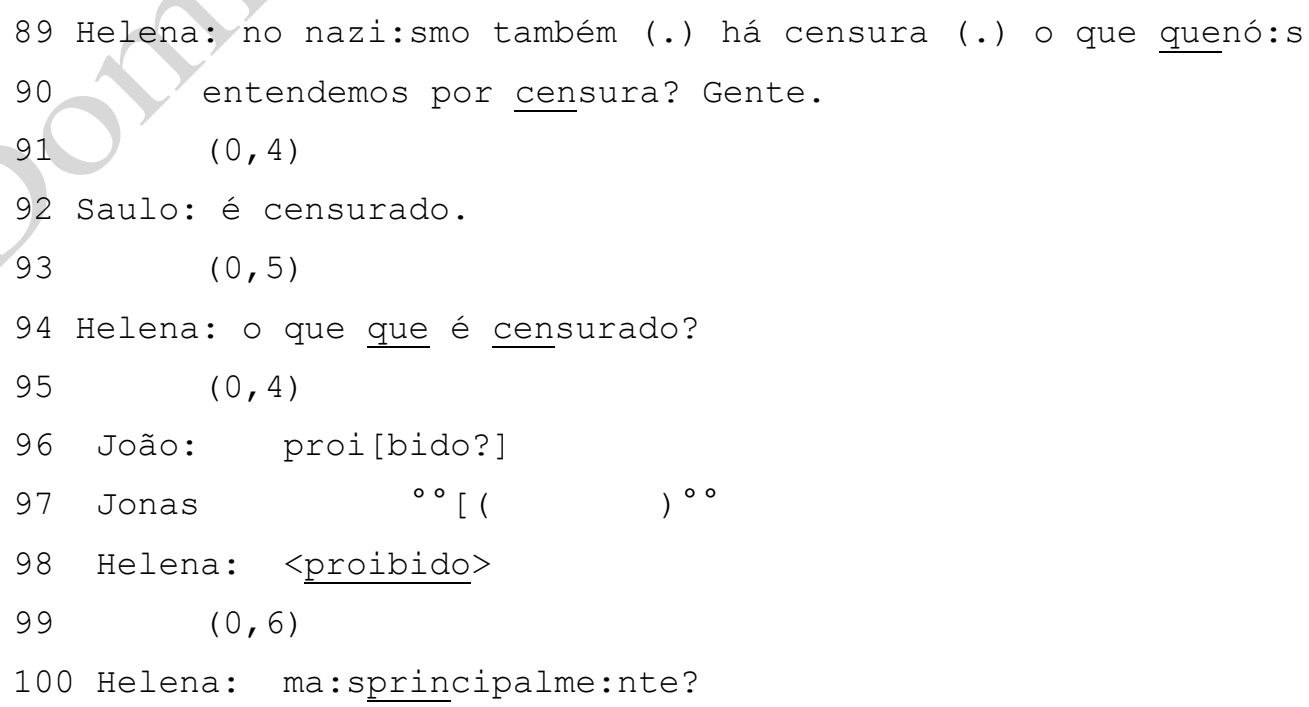




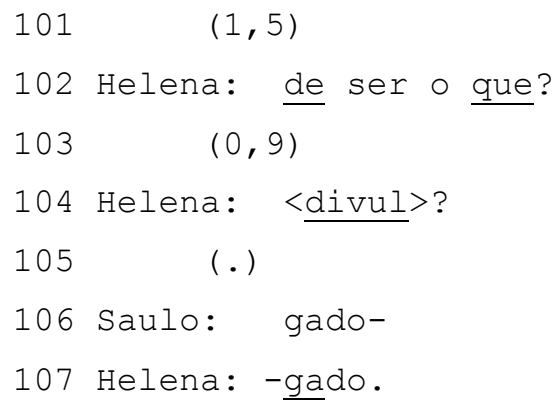

Nas linha 89 e 90, Helena, com intensidade elevada e entonação ascendente, faz uma iniciação no nazi:smo também (.) há censura (.) o que quenó:s entendemos por censura? Gente, endereçando sua fala a todos os alunos. Após quatro décimos de segundo (linha 91), Saulo se autosseleciona para fornecer a resposta, é censurado. (linha 92). Entretanto, depois de cinco décimos de segundos (linha 93), ao tomar o turno novamente, Helena não avalia a resposta de Saulo, mas produz uma outra iniciação a partir da resposta apresentada por ele (linha 92), o que que é censurado?(linha 94). Na sequencialidade, João se autosseleciona e com entonação ascendente apresenta uma resposta proi[bido?( linha 96). A entonação ascendente de sua elocução revela certa dúvida em relação à resposta e parece ser uma solicitação de antemão da avaliação por Helena. Ainda em sobreposição ao turno de João (linha 96), Jonas (linha 97) também se autosseleciona, porém, seu turno relativamente mais baixo, não é audível.

Subsequente, em adjacência, Helena ratifica a fala de João (linha 96) e avalia sua resposta como correta, repetindo-a de modo desacelerado e com tom elevado $<$ proibido $>$ (linha 98). Após seis décimos de segundo (linha 99), como não ocorre outra autosseleção em relação à questão, ela faz outra iniciação, ainda relacionada à mesma questão da linha 90, ma:sprincipalme:nte? (linha 100), sendo esta marcada pelo prolongamento de vogal, alteração na intensidade com ênfase de sílabas e entonação ascendente.

Nessa sequência interacional, convém destacar que a organização da estrutura conversacional IRA acontece de modo diferenciado em relação ao comumente evidenciado nas aulas analisadas. Helena usa essa estrutura conversacional para buscar a resposta, embora seja uma resposta já conhecida, a qual ela espera que os alunos apresentem, o que é marcado na linha 104, quando ela produz parte da resposta sinalizando para eles complementarem-na. Durante o percurso interacional, como não 
obtém a resposta, ela faz cinco iniciações (linhas 90,94,100, 102 e 104) até consegui-la ao invés de, em adjacência na linha 100, apresentar a resposta. Nesse sentido, o IRA é usado não somente para buscar uma resposta tida como correta, mas também para engajar os alunos na construção do conhecimento, o que configurou uma estrutura conversacional do IRA não transgressivo (GARCEZ, 2006).

\section{Considerações finais}

Este artigo objetivou discutir como é organizada a participação oral nas aulas de

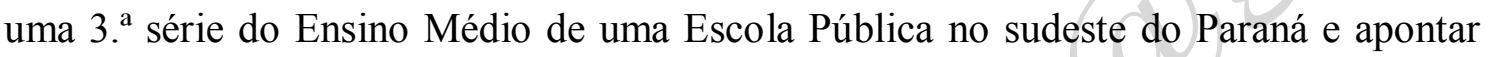
como os modos de participação podem contribuir para a construção conjunta do conhecimento.

Os resultados mostram que a participação oral dessa turma nas aulas se dava tipicamente pelo modelo interacional Iniciação, Resposta e Avaliação (IRA), o qual consiste em fazer testagens do que os alunos já sabem, o que não possibilitava oportunidades para construção conjunta de conhecimento, pois em pouco espaço de tempo após as iniciações os professores faziam as avaliações das respostas dadas pelos alunos ou quando não recebiam as respostas, os próprios professores apresentavam as respostas corretas.

No entanto, embora com menor frequência, o modelo IRA também era utilizado de uma maneira não tradicional (GARCEZ, 2006), ou seja, um modo de o professor usar o IRA para fazer iniciações, buscando levar os alunos a participarem oralmente na produção das atividades e, consequentemente, abrir espaços para a construção conjunta de conhecimento em sala de aula. Embora, nas aulas analisadas, essa maneira de usar o IRA fosse menos recorrente, era o modo pelo qual os professores conseguiam obter mais participação oral dos alunos, no entanto, mesmo assim era uma prática incipiente para contribuir para uma maior construção conjunta do conhecimento por meio da oralidade, revelando que as práticas interacionais dessa sala de aula necessitavam ser revistas e replanejadas para contribuir para uma melhor formação dos alunos.

Assim, a partir dos dados de fala-em-interação das aulas analisadas, evidencia-se a importância do modo de organização da interação nas aulas para a construção 
conjunta e participativa do conhecimento em sala de aula. Por isso, pesquisas nesse sentido contribuem para que sejam repensados os modos de organização interacional em sala de aula e também mostram que os modelos interacionais de sala de aula necessitam ser debatidos com professores em formação.

\section{Referências}

ABELEDO, M.L.O.L. Uma compreensão etnometodológica da aprendizagem de língua estrangeira na fala-em-interação de sala de aula. Tese de doutorado, Instituto de Letras, Universidade Federal do Rio Grande do Sul. Porto Alegre, 2007.

BULLA, G. A realização de atividades pedagógicas colaborativas em sala de aula de português como língua estrangeira. Dissertação de Mestrado. Porto Alegre, PPGLetras, UFRGS, 2007.

CLARK, H. O uso da linguagem. Cadernos de Tradução. Porto Alegre, n. 9, p.49-71, jan./mar. 2000.

CONCEIÇÃO, L. E. Estruturas de participação e construção conjunta de conhecimento na fala-em-interação de sala de aula de língua inglesa em uma escola pública municipal de Porto Alegre. Dissertação (Mestrado em Letras). Porto Alegre: Universidade Federal do Rio Grande do Sul, 2008.

CORONA, M. D. Fala-em-interação cotidiana e fala-em-interação institucional: uma análise de audiências criminais. In: LODER, L. L.; JUNG, N. M. Análises de fala-eminteração institucional: a perspectiva da análise da conversa etnometodológica. Campinas/SP: Mercado de Letras, 2009.

DREW, P.; HERITAGE, J. Analyzing talk at work: an introduction. In: DREW, P.; HERITAGE, J (Org.). Talk at work: interaction in institutional settings. Cambridge: Cambridge University Press, 1992. p. 3-65.

ERICKSON, F; SHULTZ, J. "O quando" de um contexto. Questões e métodos na análise da competência social. In: RIBEIRO, B.; GARCEZ, P. M. (Orgs.). Sociolinguística Interacional. São Paulo: Loyola, 2002. p. 215-234.

ERICKSON, F. Ethnographic microanalysis of interaction. In: LECOMPTE, M. D.; MILLROY, W. L. \& PREISSLE, J. (Orgs.). The handbook of qualitative research in education. Nova Iorque: Academic Press, 1992. p. 201-225. 
- Metodos cualitativos de investigacion sobre la ensinanza. In: WITTROCK, M. C. (Org.). La investigación de la enseñanza, II: metodos cualitativos y de observación. Barcelona: Paidos, 1989. p. 195-301.

. Prefácio. In: COX, M. I. P; ASSIS-PETERSON, A. As Cenas da sala de aula. Campinas: Mercado de Letras, 2001.

FORTES, M. F. Uma compreensão etnometodológica do trabalho de fazer membro na fala-em-interação de entrevista de proficiência oral em português como língua adicional. Tese de Doutorado em Linguística Aplicada. Programa de Pós-graduação em Letras. Universidade Federal do Rio Grande do Sul. Porto Alegre, 2009.

FREITAS, A. L. P.; MACHADO, Z. F. Noções fundamentais: a organização da tomada de turnos na fala-em-interação. In: LODER, L. L; JUNG, N. M. Fala-em-interação social: Introdução à Análise da Conversa Etnometodológica. Campinas/SP: Mercado de Letras, 2008, p. $59-94$.

GARCEZ, P. M. A organização da fala-em-interação na sala de aula: controle social, reprodução de conhecimento, construção conjunta de conhecimento. Calidoscópio, v.4, n. 1,2006, p. $66-80$.

- A perspectiva da Análise da Conversa Etnometodológica sobre o uso da linguagem em interação social. In: LODER, L. L; JUNG, N. M. Fala-em-interação social: Introdução à Análise da Conversa Etnometodológica. Campinas/SP: Mercado de Letras, 2008, p. $17-38$.

GOODWIN, C.; GOODWIN, M. H. Participation. In: DURANTI, A. (Ed.). A Companion to Linguistic Anthropology. Malden, Mass: Blackwell, 2004. p. 222-244.

GOODWIN, M. H. He-Said-She-Said: talk as social organization among black children. Bloomington: Indiana University Press, 1990. 371 p.

JUNG, N. M.; GONZALEZ, P. C. A organização da tomada de turnos: socialização em sala de aula. . In: LODER, L. L.; JUNG, N. M. Análises de fala-em-interação institucional: a perspectiva da Análise da Conversa Etnometodológica .Campinas/SP: Mercado de Letras, 2009.

LODER, L. L. Noções fundamentais: A organização do reparo. In: LODER, L.; JUNG, N. (Orgs.). Fala-em-interação social: Introdução à Análise da Conversa Etnometodológica. Porto Alegre: Mercado de Letras, 95-126, 2008.

. Noções fundamentais: a organização de reparo. In: LODER, L. L; JUNG, N. M. Fala-em-interação social: Introdução à Análise da Conversa Etnometodológica. Campinas/SP: Mercado de Letras, 2008, p. 59 - 94. 
. O modelo Jefferson de transcrição: Convenções e debates. In: LODER, L.; JUNG, N. (Orgs.). Fala-em-interação social: Introdução à Análise da Conversa Etnometodológica. Porto Alegre: Mercado de Letras, 126-161, 2008.

LODER, L. L; SALIMEN, P. G.; MÜLLER, M. Noções fundamentais: seqüencialidade, adjacência e preferência. In: LODER, L. L; JUNG, N. M. Fala em interação social: Introdução à Análise da Conversa Etnometodológica. Campinas/SP: Mercado de Letras, 2008, p. $39-58$.

LOPES, M.F.R. A negociação de identidades de professor na sala de aula de estágio de língua espanhola. Dissertação de mestrado em Letras. Universidade Estadual de Maringá. Maringá, 2009.

MACBETH, D. H. The relevance of repair for classroom correction. Language in Society, 33, 703-736, 2004.

MASON, J. Qualitative researching. London: Sage, 1996.

McHOUL, A. The organization of turns at formal talk in the classroom. Language in Society, 7, 182-213, 1978.

O'CONNOR, M.; MICHAELS, S. Shifting Participant Frameworks: orchestrating thinking practices in group discussion. In: HICKS, D. (Org.). Discourse, learning and schooling. Cambridge, UK: Cambridge University Press, 1996. p. 63-103.

PHILIPS, S. U. Algumas Fontes de Variabilidade Cultural na Variação da Fala. In: RIBEIRO, B. T.; GARCEZ, P. M. (Org.). Sociolinguística Interacional. São Paulo: Loyola, 2002. p. 21-43.

. Participant structures and communicative competence: Warm Springs children in community and classroom. In: DURANTI, A. (Org.). Linguistic Anthropology: a reader. Malden, Mass.: Blackwell, 2001. p. 302-317.

RAMPTON, B. Language in late modernity: Interaction in na urban school. Cambridge: Cambridge University Press, 2006.

SACKS, H.; SCHEGLOFF, E. A.; JEFFERSON, G.A simplest systematic for the organization of turn-taking for conversation. Language, Baltimore, MD, v.50, p.696$35,1974$.

Sistemática elementar para a organização da tomada de turnos para a conversa. Veredas, v.7, n. 1-2, p. 9-73, 2005.Tradução de SACKS, H., SCHEGLOFF, E. A. e JEFFERSON, G.A simplest systematic for the organization of turn-taking for conversation. Language, v. 50, 1974, p. 696-735. 
SALIMEN, P. G., CONCEIÇÃO, L. E. Reparo, correção e avaliação na fala-em interação na sala de aula. In: LODER, L. L.; JUNG, N. M. Análises de fala-eminteração institucional: a perspectiva da Análise da Conversa Etnometodológica. Campinas/SP: Mercado de Letras, 2009.

SCHEGLOFF, E; JEFFERSON, G; SACKS, H. The preference for self-correction in the organization of repair in conversation. Language, Baltimore, vol. 53, n2, pp. 361382, 1977.

SCHULZ, L. A construção da participação na fala-em-interação de sala de aula: um estudo microetnográfico sobre a participação em uma escola municipal de Porto Alegre. Dissertação de Mestrado. Porto Alegre: Programa de Pós-Graduação em Letras, 2007.

SEMECHECHEM, J. A. 2010. Letramento e identidades sociais em um município multilíngue no Paraná. 2010. Dissertação (Mestrado em Letras). Programa de Pós-graduação em Letras, Universidade Estadual de Maringá, Maringá, PR.

SINCLAIR, J. M., COULTHARD, M. Toward an analysis of discourse. Londres: Oxford University Press, 1975.

\section{Anexos}

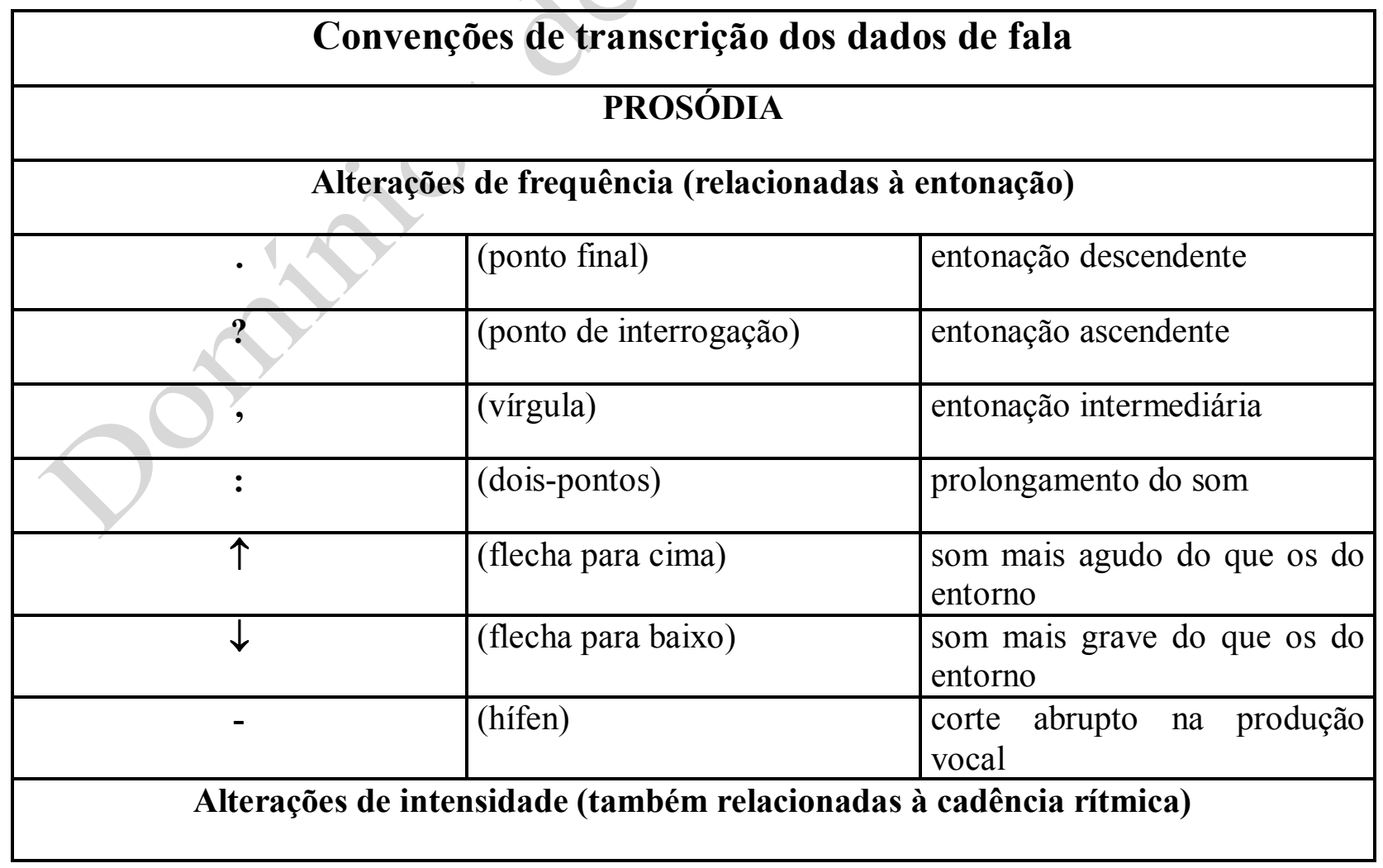




\begin{tabular}{|c|c|c|}
\hline fala & (sublinha) & ênfase em som \\
\hline FAla & (maiúscula) & $\begin{array}{l}\text { som em volume mais alto do } \\
\text { que os do entorno }\end{array}$ \\
\hline${ }^{\circ}$ fala $^{\circ}$ & (sinais de graus) & $\begin{array}{l}\text { som em volume mais baixo do } \\
\text { que os do entorno }\end{array}$ \\
\hline${ }^{\circ \circ}$ fala $^{\circ \circ}$ & (sinais de graus duplos) & $\begin{array}{l}\text { som em } \quad \text { volume } \\
\text { destacadamente mais baixo do } \\
\text { que os do entorno }\end{array}$ \\
\hline \multicolumn{3}{|c|}{ Demais alterações também relacionadas à cadência rítmica } \\
\hline$>$ fala $<$ & $\begin{array}{l}\text { (sinais de maior do que e } \\
\text { menor do que) }\end{array}$ & fala acelerada \\
\hline$<$ fala $>$ & $\begin{array}{l}\text { (sinais de menor do que } \mathrm{e} \\
\text { maior do que) }\end{array}$ & fala desacelerada \\
\hline \multicolumn{3}{|c|}{ Pausas (também relacionadas à cadência rítmica) } \\
\hline$(2,4)$ & (números entre parênteses) & $\begin{array}{l}\text { medida de silêncio (em segundos } \\
\text { e décimos de segundos) }\end{array}$ \\
\hline (.) & (ponto entre parênteses) & $\begin{array}{l}\text { silêncio de menos de } 2 \text { décimos } \\
\text { de segundo }\end{array}$ \\
\hline \multicolumn{3}{|c|}{ DEMAIS SINALIZAÇÕES REFERENTES À FALA } \\
\hline ) & (parênteses vazios) & $\begin{array}{l}\text { segmento de fala que não pôde } \\
\text { ser transcrito }\end{array}$ \\
\hline (palavra & $\begin{array}{|llll|}\begin{array}{l}\text { segmento } \\
\text { parênteses })\end{array} & \text { de } & \text { fala } & \text { entre } \\
\end{array}$ & $\begin{array}{l}\text { fala transcrita, mas com dúvida } \\
\text { do transcritor }\end{array}$ \\
\hline & (colchetes) & $\begin{array}{l}\text { fala sobreposta (mais de um } \\
\text { interlocutor falando ao mesmo } \\
\text { tempo) }\end{array}$ \\
\hline & (sinal de igual) & elocuções contíguas \\
\hline hh & (série de h's) & indica aspiração ou riso \\
\hline palavra & $\begin{array}{l}\text { (itálico, logo na linha abaixo } \\
\text { da palavra ou frase em outra } \\
\text { língua, que não o português) }\end{array}$ & tradução para o português \\
\hline palavra & $\begin{array}{l}\text { (citação em itálico da fala no } \\
\text { texto) }\end{array}$ & \begin{tabular}{|l} 
citações de elocuções dos \\
excertos no corpo do texto
\end{tabular} \\
\hline Maria & (pseudônimo) & $\begin{array}{l}\text { nome fictício para a } \\
\text { identificação do participante da } \\
\text { interação }\end{array}$ \\
\hline
\end{tabular}

Artigo recebido em: 30.03.2012

Artigo aprovado em: 20.06.2012 